\title{
Future Therapies for IgE-Mediated Food Allergy
}

\author{
M. Cecilia Berin
}

Published online: 11 March 2014

(C) Springer Science + Business Media New York 2014

\begin{abstract}
Food allergy is prevalent, affecting approximately $4-8 \%$ of children. There is no currently approved treatment for food allergy, and while strict allergen avoidance is recommended it is difficult to achieve. Therefore, accidental exposures and reactions are common. There is an urgent need for the development of therapeutic approaches that will improve the health and quality of life of children with food allergy. The majority of current clinical research focus is on specific food allergen immunotherapy through oral, sublingual, or epicutaneous routes. Pre-clinical research has focused on making improvements to the safety and efficacy of allergen immunotherapy through modifications of allergen structure and addition of immunomodulatory factors. The number of novel therapeutics for food allergy reaching the level of clinical trials remains disappointingly low, and there is a need for an expansion of pre-clinical research to provide safe, practical, and novel approaches to the treatment of food allergy.
\end{abstract}

Keywords Food allergy · Immunotherapy ·

Anaphylaxis · Tolerance

\section{Introduction}

IgE-mediated food allergies are prevalent, affecting approximately $4-8 \%$ of children and 3-4\% of adults. Ingestion of foods triggers activation of allergic effector cells, including mast cells and basophils, by cross-linking

M. C. Berin $(\bowtie)$

Division of Pediatric Allergy and Immunology, Jaffe Food Allergy Institute, Icahn School of Medicine at Mount Sinai, One Gustave L. Levy Place, Box 1198, New York, NY 10029, USA e-mail: cecilia.berin@mssm.edu
IgE bound to the high-affinity FceRI receptor on the cell surface. Degranulation of these cells is responsible for acute allergic symptoms that can affect the skin, lung, and gastrointestinal tract, and in severe cases may affect the cardiovascular system. For a comprehensive and current review of food allergy, readers are referred to [1•]. There is currently no approved treatment beyond allergen avoidance and acute management of symptoms in the case of accidental exposure. While allergen avoidance is theoretically a very effective management strategy, issues such as crosscontamination of foods during preparation and difficulties in interpreting food labeling make accidental exposures and reactions an unavoidable occurrence for those with food allergies. Furthermore, for children with multiple food allergies, dietary restrictions can have negative consequences on nutritional status. Therefore, treatments are needed that are both safer and more effective than the current standard of care. There are a number of clinical studies completed or in progress assessing the safety and efficacy of different forms of allergen immunotherapy for the treatment of food allergy. To date there are limited reports of long-term follow-up of subjects after oral immunotherapy (OIT), with mixed results on the achievement of long-term tolerance [2,3]. Most reports agree that a minority of those starting treatment achieve long-term tolerance, and therefore there is a need to develop better therapies for the treatment of food allergy. The focus of this manuscript will be on pre-clinical studies supporting the next wave of human trials.

\section{Immune Mechanisms of IgE-Mediated Food Allergy}

Production of allergen-specific IgE is central to the pathogenesis of food allergy. Although non-IgE-mediated 
food allergies such as food protein-induced enterocolitis syndrome exist, the mechanism of reactions is distinct from the more common IgE-mediated food allergies, and those clinical entities will not be addressed in this manuscript. Presence of allergen-specific IgE is not sufficient to predict clinical reactivity, but increasing levels of $\operatorname{IgE}$ are associated with increasing risk of clinical reactivity, and values that are $95 \%$ predictive of reactivity have been established for several foods $[4,5]$. IgE binds with high affinity to FceRI, a receptor composed of an $\alpha$ chain, $\beta$ chain, and two $\gamma$ chains on mast cells and basophils. Cross-linking of IgE on basophils and mast cells leads to degranulation of pre-formed granule contents, rapid production of lipid mediators, and a slower synthesis of cytokines. Factors that may contribute to clinical reactivity beyond the amount of $\operatorname{IgE}$ include affinity of $\operatorname{IgE}$ for the allergen or the ratio of specific to total IgE [6]. Functional assays of effector cell activation, such as skin prick testing, which reflects mast cell activation, or in vitro basophil activation assays have in some cases been shown to have added value when used together with specific IgE levels [7]. However, the gold standard for diagnosis remains the doubleblind placebo-controlled food challenge. The discord between sensitization and clinical reactivity has led to the speculation that non-IgE-mediated pathways may contribute to anaphylaxis. In mouse, IgG antibodies can contribute to anaphylaxis through activation of macrophages or basophils $[8,9]$. IgG-mediated activation of human neutrophils has been shown to occur with antigen stimulation [10,11], but a contribution of food-specific IgG to food-induced reactions in humans has not yet been identified. IgG-mediated anaphylaxis has been demonstrated primarily with high-dose intravenous allergen challenge of mice; studies using more moderate doses or oral allergen challenge have shown that mast cells and IgE are the major mechanisms of food-induced anaphylaxis [12-14]. Identifying all contributing mechanisms of anaphylaxis in humans may be important for developing an effective therapy.

Pathways that suppress anaphylaxis may also contribute to the discordance between the presence of food-specific IgE and clinical reactivity. Food-specific IgG4 and IgA antibodies compete with IgE for allergen binding, and aggregation of the FceRI receptor with the Fc $\gamma \mathrm{RIIb}$ receptor (by IgE-allergen-IgG1 complexes in human) provides negative signaling to allergic effector cells.

Mediators responsible for symptoms of food-induced systemic anaphylaxis include histamine and platelet-activating factor (PAF), shown by data from both mouse and human [15-17]. In contrast, gastrointestinal manifestations of food allergy in mice are not driven by histamine, but by $\mathrm{PAF}$ and serotonin [18].
Production of allergen-specific $\operatorname{IgE}$ is supported by the presence of Th2-biased antigen-specific $\mathrm{CD}^{+} \mathrm{T}$ cells. Subjects with IgE-mediated peanut allergy have an increased frequency of peanut-specific $\mathrm{T}$ cells compared to healthy controls and produce Th2 cytokines that are absent from peanut-specific $\mathrm{T}$ cells from healthy controls or those who have outgrown their peanut allergy [19-21]. An increase in allergen-responsive regulatory $\mathrm{T}$ cells has been demonstrated in subjects who have outgrown their nonIgE-mediated milk allergy [22] or are sensitized but tolerant to extensively heated forms of milk [23].

Based on our current knowledge of the immune basis of food allergy, therapeutic strategies have focused on reducing levels of allergen-specific IgE, enhancing levels of allergen-specific IgG or IgA, suppressing Th2 effector cells, or enhancing regulatory $\mathrm{T}$ cells through a variety of antigen-specific and antigen non-specific strategies.

\section{Allergen Immunotherapy}

Subcutaneous allergen immunotherapy is currently used for desensitization to aeroallergens and bee venom. Administration of peanut immunotherapy by the subcutaneous route was attempted and abandoned because of severe adverse reactions to the therapy [24, 25]. Oral desensitization to foods had been described in early case reports and series and in the past 10 years has been the subject of intense research focus. A search of trials listed at "clinicaltrials.gov" using the search terms "food allergy" or "food hypersensitivity" and "immunotherapy" provides 32 current and completed trials using OIT, 10 using sublingual immunotherapy (SLIT), and 5 using epicutaneous immunotherapy (EPIT). All but three of the trials use allergen immunotherapy without any additional adjuvant or immunomodulatory agents. Results are promising when desensitization, defined as protection from food-induced reactions while receiving therapy, is used as a primary outcome [26-28]. However, concerns about safety and long-term disease-modifying efficacy persist. Adverse reactions to OIT are not uncommon, and a significant number of subjects experience adverse reactions of sufficient severity or persistence to prevent continuation of immunotherapy. Despite the number of trials listed as ongoing or completed, most have a small number of subjects, are not placebo-controlled, and were not designed to look at long-term outcomes with tolerance challenges to assess whether treatment effects persist off therapy. In addition, different foods may respond differently to immunotherapy. Therefore, it has been difficult to obtain an accurate assessment of long-term efficacy of immunotherapy for foods. For a more comprehensive summary of the state of allergen immunotherapy for the treatment of food allergy, readers are 
referred to recent reviews on the topic [29, 30]. Even the most successful trials report that at least half of patients who begin immunotherapy do not achieve successful long-term tolerance $[2,3,31 \bullet, 32]$, and therefore despite the pending outcome of long-term follow-up of current immunotherapy trials there remains an urgent need to improve the safety and efficacy of these still-experimental treatments.

The immune basis of tolerance induced by allergen immunotherapy for food allergy is still the subject of intensive research, but immunotherapy is associated with elevations in allergen-specific IgG4 and IgA, and reductions in diversity of epitopes recognized by allergen-specific IgE, skin prick test wheal size, allergen-induced basophil activation, and allergen-induced Th2 cytokine production [2, 33-35]. These parameters are associated with immunotherapy, but so far there have been no biomarkers described that successfully predict tolerance versus desensitization in response to immunotherapy. Tolerant individuals have a more robust IgG4 induction early in therapy compared to those who are desensitized, and a greater suppression of skin prick test wheal size [31•], but there is little definitive information yet on the mechanistic basis of sustained tolerance versus desensitization to foods. The inclusion of mechanistic studies in several current immunotherapy trials with tolerance challenges in the study design will likely yield significant new information in the next few years.

\section{Routes of Immunotherapy}

OIT is the farthest ahead of any immunotherapy treatments in showing efficacy for the treatment of food allergy. The default immune response to antigens delivered orally is immune tolerance mediated by regulatory $\mathrm{T}$ cells. However, as the oral route is also the route that normally leads to food-induced allergic reactions, safety is a major concern with OIT. SLIT and EPIT were proposed as routes that could have a significantly better safety profile yet retain the ability to induce tolerance. Sublingual antigenpresenting cells induce regulatory $\mathrm{T}$ cells similar to those of the intestinal tract [36], and the limited antigen dose applied to this route improves the safety profile [32]. The improvement in safety appears to be at some cost to efficacy [32, 37], although some groups report promising efficacy with SLIT for treatment of peanut allergy [38, 39]. Pre-clinical studies in mice show that EPIT leads to suppression of allergic inflammation in the lung and in the gastrointestinal tract, with a reduction of IgE, enhancement of IgG, and suppression of Th2 effector responses [40, 41]. In mice, application of antigen to non-damaged skin leads to acquisition of antigen by cutaneous dendritic cells that promote the development of regulatory $\mathrm{T}$ cells [42]. Data on the efficacy of EPIT for the treatment of peanut allergy are pending, with several trials currently in progress.

\section{Anti-IgE with Immunotherapy}

Three trials reported in clinicaltrials.gov include anti-IgE therapy, which is hypothesized not only to enhance the safety of the immunotherapy treatment, but also to improve efficacy by suppressing IgE-facilitated antigen presentation. Anti-IgE therapy increases the threshold of reactivity to peanut in peanut-allergic patients [43]. Two pilot studies have reported rush oral desensitization to milk and peanut in anti-IgE-treated patients $[44,45]$. Although the data are clear that anti-IgE therapy increases the threshold of allergen reactivity in vivo and with human blood basophils, the data on the impact of anti-IgE therapy on presentation of antigen to T cells are less compelling [46]. Studies of immunotherapy and anti-IgE therapy for asthma and allergic rhinitis show a significant improvement of symptoms with anti-IgE therapy compared to immunotherapy alone, but the symptom improvement is only observed while anti-IgE therapy is maintained [47]. Results from placebo-controlled studies looking at long-term efficacy of immunotherapy with and without anti-IgE treatment for food allergy are pending.

\section{Modified Allergens}

One approach to make allergens safer for immunotherapy is to modify their structure to reduce IgE binding. Some allergens can be modified in this way simply through heating. The majority of children allergic to egg or milk can tolerate these antigens in baked goods or in forms that have been extensively heated [48, 49]. Heating denatures the proteins and destroys conformational epitopes, and there are also matrix effects that influence digestion and absorption of the allergens. Milk- or egg-allergic children enrolled in intervention studies in which they incorporated extensively heated milk or egg into the diet outgrew their unheated egg or milk allergy more quickly than a control group that received standard of care [50, 51], and this inclusion of milk or egg was associated with changes in immune parameters consistent with an immunotherapeutic response (elevation in $\mathrm{IgG} 4$, decreases in allergen-specific IgE). It is not known whether these immune changes underlie the generation of tolerance or are a biomarker of antigen exposure. In a murine model of OIT for foodinduced anaphylaxis, extensively heated ovomucoid was unable to induce symptoms in mice yet when applied as OIT was as effective as native ovomucoid for the prevention of anaphylaxis [52].

Heating to reduce allergenicity is applicable to egg or milk, but not to antigens such as peanut where high heat 
increases allergenicity rather than reducing it. Digestion of cashew extracts with pepsin reduces the IgE binding of extracts, and in a mouse model of systemic immunotherapy, performed as well as intact cashew extract in protecting mice from cashew-induced anaphylaxis [53]. In contrast, enzyme hydrolysates of peanut have been shown to retain IgE binding and basophil activation potential [54]. Extract digests are unlikely to be used as subcutaneous immunotherapy because of difficulty in standardization and safety issues, but the pre-clinical study with cashew paves the way for peptide immunotherapy for nut allergy. Peptides that are too short to cross-link IgE but maintain $\mathrm{T}$ cell epitopes would have the capacity to generate T cell-mediated immunomodulation. Immuno-dominant peptides in the peanut allergens Ara h 1 [55] and Ara h 2 [56] have recently been identified with the goal of developing peptide immunotherapy. Peptide immunotherapy has been shown in pre-clinical studies as well as preliminary human trials to be effective for the treatment of cat allergy [57]. In addition to digestion and heating, allergens can be modified by chemical modification. Reduction and alkylation of Ara $\mathrm{h} 2$ and Ara $\mathrm{h} \mathrm{6}$, the major allergens of peanut, reduces $\operatorname{IgE}$ binding to the allergens [58]. In vivo studies demonstrate that reduced and alkylated Ara h 2 has decreased capacity to trigger anaphylaxis [59]. Experimental immunotherapy with Ara h 2 and Ara h 6 in mice is sufficient to protect against anaphylaxis to whole peanut extract [60], suggesting potential for these modified allergens as a safer form of immunotherapy.

Glycosylation of allergens can significantly modify their immunogenicity and allergenicity. Carbohydrate structures can both promote and suppress allergenicity. There is evidence that exposure of some allergens to high heat can enhance allergenicity through glycation, which allows for recognition of the allergens by pattern recognition receptors on antigen-presenting cells [61, 62]. The peanut allergen Ara h 1 binds to the lectin receptor DC-SIGN on human dendritic cells through carbohydrate residues and has Th2-promoting activity through a carbohydratedependent mechanism [63]. But glycosylation can also result in enhanced immune tolerance. The antigen BSA, when heavily conjugated with mannosides, binds to the DC-SIGN homolog SIGN-R1 in mice and promotes the development of immune tolerance through IL-10-producing regulatory $\mathrm{T}$ cells [64]. This conjugated antigen has enhanced affinity for dendritic cells of the intestinal lamina propria. Mannosylated ovalbumin has been shown in a murine OIT model to be significantly better than ovalbumin for clinical protection against ovalbumin-induced anaphylaxis [65]. It is not clear whether these effects are due to more efficient targeting to normally tolerogenic dendritic cells or whether binding to pattern recognition receptors such as SIGN-R1 in mice alters the phenotype of the dendritic cell to promote the generation of regulatory $\mathrm{T}$ cells. It was recently shown that the intestinal mucin Muc2 enhanced the regulatory phenotype of $\mathrm{CD} 103^{+}$intestinal dendritic cells through upregulation of known tolerogenic pathways (TGF- $\beta$, RALDH, IL-10) [66•]. Muc2 bound to a complex of galectin 3, dectin-1, and Fc $\gamma$ RIIb on the surface of dendritic cells, resulting in the promotion of a tolerogenic phenotype and expansion of $\mathrm{Foxp}^{+}$regulatory $\mathrm{T}$ cells. Thus, allergens modified with appropriate carbohydrate structures may have potential as immunotherapeutic agents for the treatment of food allergy.

\section{Adjuvants for Allergen Immunotherapy}

Administration of allergen alone may be insufficient to fundamentally change the nature of the adaptive immune response to that allergen. Adjuvants that amplify either a Th1 response or a regulatory response may be necessary to sufficiently suppress the Th2-skewed immunity that drives the allergic response to foods. Many of these adjuvants are of microbial origin and range from whole heat-killed bacteria to co-administered purified microbial products to fusion proteins incorporating allergen and adjuvant in one. By binding to innate pattern recognition receptors on antigen-presenting cells, these adjuvants are thought to drive the $\mathrm{T}$ cell response away from a Th2 response. Adjuvants not only modify the nature of the immune response, but amplify the response such that significantly lower doses of allergen may be sufficient for an immunotherapeutic effect.

Subcutaneous administration of heat-killed Listeria monocytogenes together with native or modified peanut protein was shown to suppress peanut-induced anaphylaxis in mice [67] and dogs [68] by driving a strong Th1 response. A next generation approach used $E$. coli to express Ara h 1-3 allergens that had been modified to remove $\operatorname{IgE}$ binding epitopes [69॰]. Heat-killed E. coli bearing modified Ara h 1-3 was administered rectally to peanut-allergic mice and resulted in sustained clinical protection of mice against peanut-induced anaphylaxis. This is a unique example of a novel immunotherapy for the treatment of peanut allergy that has been brought to clinical trial [70•]. Surprisingly, rectal administration of the therapeutic resulted in adverse reactions including anaphylactic reactions in two of ten peanut-allergic subjects tested. These results highlight the tremendous difficulty of administering a safe allergen immunotherapy to foodallergic subjects. Even allergens mutated to remove IgEbinding epitopes, and delivered rectally within bacterial encapsulation at microgram to low milligram doses, were sufficient to induce anaphylaxis in $20 \%$ of subjects.

Other pre-clinical adjuvant approaches to the treatment of food allergy have involved synthetic oligonucleotides 
containing $\mathrm{CpG}$ motifs, which when administered together with peanut protein was significantly better than peanut alone in protecting mice from peanut-induced anaphylaxis [71]. CpG motifs activate dendritic cells and B cells via TLR9. A ragweed allergen-CpG conjugate was developed for immunotherapy, but despite promising results in the suppression of allergic symptoms [72], there have been no further published human trials on $\mathrm{CpG}$-allergen conjugates. $\mathrm{CpG}$ packaged within virus-like nanoparticles have been tested in asthmatic patients with significant improvements in symptom scores [73], but this approach has not utilized any allergen-specific component. Viruslike particles containing the cat allergen Fel d 1 have been successfully used in pre-clinical studies of cat allergy [74]. These virus-like particles have not yet been tried for food allergy. A flagellin-ovalbumin fusion protein was reported to be highly effective in the prevention of symptoms in a model of gastrointestinal food allergy and modestly effective when administered as a therapeutic [75]. Flagellin binds to TLR5, which is highly expressed on some gastrointestinal dendritic cell subsets. Studies are clearly needed to optimize the choice of adjuvants (including Th1 vs. Treg optimization) as well as to improve safety of administration for immunotherapy with allergen-adjuvant combinations.

\section{Tolerogenic Allergen-Cell Conjugates}

One interesting approach to the generation of food allergen-specific tolerance has been the administration of syngeneic apoptotic cells coated with peanut allergen [76•]. Peanut-allergic mice were treated with intravenous syngeneic spleen cells that had been chemically conjugated with peanut. The conjugation procedure has previously been shown to induce apoptosis of the donor cells, which may contribute important tolerogenic signals to the recipient antigen-presenting cells that engulf the cell-allergen conjugate [77]. This approach was shown to be effective in both an asthma model and a food allergy model. The challenge of how to administer such an immunotherapy safely to food-allergic patients remains to be solved, although a similar approach was well tolerated in a phase I trial for multiple sclerosis [78].

\section{Fc $\gamma$-Allergen Conjugates}

An approach to making allergens safer for immunotherapy has been to prepare fusion proteins between allergen and human Fc $\gamma$ chains. The hypothesis behind these constructs is that the Fc $\gamma$ chain will bind to the inhibitory receptor Fc $\gamma$ RIIb simultaneously to binding to IgE on the surface of effector cells including basophils and mast cells. Inhibitory signaling via Fc $\gamma \mathrm{RIIb}$ then shuts off activation of the allergic effector cells. Liu et al. [79] developed an Ara h 2-Fc $\gamma$ fusion protein and tested its efficacy as immunotherapy in peanut-allergic mice. The fusion protein did not itself induce anaphylaxis in peanut-sensitized mice. The construct was not tried as a conventional immunotherapy, but pre-treatment of mice with the Ara h 2-Fc $\gamma$ fusion protein modestly suppressed some measures of peanut-induced anaphylaxis.

\section{Allergen Non-specific Therapies}

For patients with sensitization to multiple foods, allergen immunotherapy with specialized allergen-adjuvant constructs may be of limited value. Single food immunotherapy has shown some evidence for bystander protection in mouse models [80] and in humans (assessing basophil activation to an unrelated food allergen) [81]. But other approaches have been tried in which allergen administration is not a feature of the therapy. This includes herbal medications that have immunomodulatory effects on basophils, mast cells, and T lymphocytes [82, 83]. Soy isoflavones have been shown to prevent sensitization through actions on dendritic cells, but when given after sensitization has already occurred can also suppress peanut-induced anaphylaxis [84]. Pharmacologic approaches include treatment with Janus kinase inhibitors $[85,86]$ and mTOR inhibitors, both of which are immunomodulatory and suppress mast cell expansion in the gastrointestinal tract. Anti-IgE treatment, as previously mentioned, increases the threshold of reactivity to peanut [43, 87], but has not been adopted as a therapeutic approach for food allergy outside of its addition to OIT in experimental settings.

There is significant interest in probiotics and the possibility of manipulating the microbiome for therapeutic purposes. Meta-analyses of probiotics for the treatment of allergic disease have shown a protective effect on allergic sensitization, but only when supplementation is started prenatally through maternal ingestion [88]. It was recently found that clostridia strains promote the development of regulatory $\mathrm{T}$ cells in the intestine [89], and when a mix of human clostridia strains were administered to mice, they could suppress the development of food allergy [90•]. It remains to be seen whether this type of approach could be used therapeutically, either alone or in the context of allergen immunotherapy.

\section{Conclusions}

There are no currently available approved therapies for food allergy. The majority of clinical research focus is currently devoted to allergen immunotherapy by the oral, sublingual, or epicutaneous routes, but improvements in safety and efficacy are needed. Pre-clinical work on food 
allergy immunotherapy safety has primarily focused on modifications to allergen structure, while improvements in efficacy are focused on adjuvant optimization at the preclinical level. Modification of the intestinal microbiome may offer a new approach to therapy for food allergy. There is a need for more pre-clinical studies to provide novel and unique approaches that are practical and translatable for use in human trials.

Disclosure M. Cecilia Berin declares that she has no conflict of interest.

Human and Animal Rights and Informed Consent This article does not contain any studies with human or animal subjects performed by any of the authors.

\section{References}

Papers of particular interest, published recently, have been highlighted as:

- Of importance

1. - Sicherer SH, Sampson HA. Food allergy: epidemiology, pathogenesis, diagnosis, and treatment. J Allergy Clin Immunol. 2013. doi:10.1016/j.jaci.2013.11.020. A current and comprehensive review of the field of food allergy.

2. Vickery BP, Scurlock AM, Kulis M, et al. Sustained unresponsiveness to peanut in subjects who have completed peanut oral immunotherapy. J Allergy Clin Immunol. 2013. doi:10.1016/j. jaci.2013.11.007.

3. Keet CA, Seopaul S, Knorr S, Narisety S, Skripak J, Wood RA. Long-term follow-up of oral immunotherapy for cow's milk allergy. J Allergy Clin Immunol. 2013;132(3):737-9.

4. Sampson HA. Utility of food-specific IgE concentrations in predicting symptomatic food allergy. J Allergy Clin Immunol. 2001;107(5):891-6.

5. Komata T, Soderstrom L, Borres MP, Tachimoto H, Ebisawa M. The predictive relationship of food-specific serum IgE concentrations to challenge outcomes for egg and milk varies by patient age. J Allergy Clin Immunol. 2007;119(5):1272-4.

6. Christensen LH, Holm J, Lund G, Riise E, Lund K. Several distinct properties of the $\mathrm{IgE}$ repertoire determine effector cell degranulation in response to allergen challenge. J Allergy Clin Immunol. 2008;122(2):298-304.

7. Knight AK, Shreffler WG, Sampson HA, et al. Skin prick test to egg white provides additional diagnostic utility to serum egg white-specific IgE antibody concentration in children. J Allergy Clin Immunol. 2006;117(4):842-7.

8. Finkelman FD. Anaphylaxis: lessons from mouse models. J Allergy Clin Immunol. 2007;120(3):506-15; quiz 507-16.

9. Tsujimura $\mathrm{Y}$, Obata $\mathrm{K}$, Mukai $\mathrm{K}$, et al. Basophils play a pivotal role in immunoglobulin-G-mediated but not immunoglobulin-Emediated systemic anaphylaxis. Immunity. 2008;28(4):581-9.

10. Jonsson F, Mancardi DA, Zhao W, et al. Human FcgammaRIIA induces anaphylactic and allergic reactions. Blood. 2012;119(11): 2533-44.

11. Khodoun MV, Strait R, Armstrong L, Yanase N, Finkelman FD. Identification of markers that distinguish IgE- from IgG-mediated anaphylaxis. Proc Natl Acad Sci USA. 2011;108(30):12413-8.
12. Arias K, Chu DK, Flader K, et al. Distinct immune effector pathways contribute to the full expression of peanut-induced anaphylactic reactions in mice. J Allergy Clin Immunol. 2011;127(6):1552-61, e1.

13. Sun J, Arias K, Alvarez D, et al. Impact of CD40 ligand, B cells, and mast cells in peanut-induced anaphylactic responses. J Immunol. 2007;179(10):6696-703.

14. Smit JJ, Willemsen K, Hassing I, et al. Contribution of classic and alternative effector pathways in peanut-induced anaphylactic responses. PLoS ONE. 2011;6(12):e28917. doi:10.1371/journal. pone.0028917.

15. Vadas P, Gold M, Perelman B, et al. Platelet-activating factor, PAF acetylhydrolase, and severe anaphylaxis. N Engl J Med. 2008;358(1):28-35.

16. Vadas P, Perelman B, Liss G. Platelet-activating factor, histamine, and tryptase levels in human anaphylaxis. J Allergy Clin Immunol. 2013;131(1):144-9.

17. Arias K, Baig M, Colangelo M, et al. Concurrent blockade of platelet-activating factor and histamine prevents life-threatening peanut-induced anaphylactic reactions. J Allergy Clin Immunol. 2009;124(2):307-14, e1-2.

18. Brandt EB, Strait RT, Hershko D, et al. Mast cells are required for experimental oral allergen-induced diarrhea. J Clin Investig. 2003;112(11):1666-77.

19. DeLong JH, Simpson KH, Wambre E, James EA, Robinson D, Kwok WW. Ara h 1-reactive T cells in individuals with peanut allergy. J Allergy Clin Immunol. 2011;127(5):1211-8, e3.

20. Prussin C, Lee J, Foster B. Eosinophilic gastrointestinal disease and peanut allergy are alternatively associated with $\mathrm{IL}-5+$ and IL-5(-) T(H)2 responses. J Allergy Clin Immunol. 2009;124(6): 1326-32, e6.

21. Turcanu V, Maleki SJ, Lack G. Characterization of lymphocyte responses to peanuts in normal children, peanut-allergic children, and allergic children who acquired tolerance to peanuts. J Clin Investig. 2003;111(7):1065-72.

22. Karlsson MR, Rugtveit J, Brandtzaeg P. Allergen-responsive $\mathrm{CD} 4{ }^{+} \mathrm{CD} 25^{+}$regulatory $\mathrm{T}$ cells in children who have outgrown cow's milk allergy. J Exp Med. 2004;199(12):1679-88.

23. Shreffler WG, Wanich N, Moloney M, Nowak-Wegrzyn A, Sampson HA. Association of allergen-specific regulatory T cells with the onset of clinical tolerance to milk protein. J Allergy Clin Immunol. 2009;123(1):43-52, e7.

24. Nelson HS, Lahr J, Rule R, Bock A, Leung D. Treatment of anaphylactic sensitivity to peanuts by immunotherapy with injections of aqueous peanut extract. J Allergy Clin Immunol. 1997;99(6 Pt 1):744-51.

25. Oppenheimer JJ, Nelson HS, Bock SA, Christensen F, Leung DY. Treatment of peanut allergy with rush immunotherapy. J Allergy Clin Immunol. 1992;90(2):256-62.

26. Skripak JM, Nash SD, Rowley H, et al. A randomized, doubleblind, placebo-controlled study of milk oral immunotherapy for cow's milk allergy. J Allergy Clin Immunol. 2008;122(6): 1154-60.

27. Jones SM, Pons L, Roberts JL, et al. Clinical efficacy and immune regulation with peanut oral immunotherapy. J Allergy Clin Immunol. 2009;124(2):292-300, 300, e1-97.

28. Varshney P, Jones SM, Scurlock AM, et al. A randomized controlled study of peanut oral immunotherapy: clinical desensitization and modulation of the allergic response. J Allergy Clin Immunol. 2011;127(3):654-60.

29. Moran TP, Vickery BP, Burks AW. Oral and sublingual immunotherapy for food allergy: current progress and future directions. Curr Opin Immunol. 2013;25(6):781-7.

30. Sampson HA. Peanut oral immunotherapy: is it ready for clinical practice? J Allergy Clin Immunol Pract. 2013;1(1):15-21. 
31. Burks AW, Jones SM, Wood RA, et al. Oral immunotherapy for treatment of egg allergy in children. $N$ Engl $J$ Med. 2012;367(3):233-43. The first double-blind placebo-controlled trial to distinguish between desensitization and sustained nonresponsiveness, and to correlate these clinical responses with immune parameters.

32. Keet CA, Frischmeyer-Guerrerio PA, Thyagarajan A, et al. The safety and efficacy of sublingual and oral immunotherapy for milk allergy. J Allergy Clin Immunol. 2012;129(2):448-55, e1-5.

33. Jones SM, Pons L, Roberts JL, et al. Clinical efficacy and immune regulation with peanut oral immunotherapy. J Allergy Clin Immunol. 2009;124(2):292-300.

34. Kulis M, Saba K, Kim EH, et al. Increased peanut-specific IgA levels in saliva correlate with food challenge outcomes after peanut sublingual immunotherapy. J Allergy Clin Immunol. 2012;129:1159-62.

35. Vickery BP, Lin J, Kulis M, et al. Peanut oral immunotherapy modifies $\mathrm{IgE}$ and $\mathrm{IgG} 4$ responses to major peanut allergens. J Allergy Clin Immunol. 2013;131(1):128-34, e1-3.

36. Mascarell L, Lombardi V, Louise A, et al. Oral dendritic cells mediate antigen-specific tolerance by stimulating $\mathrm{TH} 1$ and regulatory CD4 ${ }^{+}$T cells. J Allergy Clin Immunol. 2008;122(3):603-9, e5.

37. Fleischer DM, Burks AW, Vickery BP, et al. Sublingual immunotherapy for peanut allergy: a randomized, double-blind, placebo-controlled multicenter trial. J Allergy Clin Immunol. 2013;131(1):119-27, e1-7.

38. Kim EH, Bird JA, Kulis M, et al. Sublingual immunotherapy for peanut allergy: clinical and immunologic evidence of desensitization. J Allergy Clin Immunol. 2011;127(3):640-6, e1.

39. Chin SJ, Vickery BP, Kulis MD, et al. Sublingual versus oral immunotherapy for peanut-allergic children: a retrospective comparison. J Allergy Clin Immunol. 2013;132(2):476-8, e2.

40. Mondoulet L, Dioszeghy V, Ligouis M, Dhelft V, Dupont C, Benhamou PH. Epicutaneous immunotherapy on intact skin using a new delivery system in a murine model of allergy. Clin Exp Allergy. 2010;40(4):659-67.

41. Mondoulet L, Dioszeghy V, Vanoirbeek JA, Nemery B, Dupont $\mathrm{C}$, Benhamou PH. Epicutaneous immunotherapy using a new epicutaneous delivery system in mice sensitized to peanuts. Int Arch Allergy Immunol. 2011;154(4):299-309.

42. Mondoulet L, Dioszeghy V, Puteaux E, et al. Intact skin and not stripped skin is crucial for the safety and efficacy of peanut epicutaneous immunotherapy (EPIT) in mice. Clin Transl Allergy. 2012. doi:10.1186/2045-7022-2-22.

43. Leung DY, Sampson HA, Yunginger JW, et al. Effect of anti-IgE therapy in patients with peanut allergy. N Engl J Med. 2003; 348(11):986-93.

44. Nadeau KC, Schneider LC, Hoyte L, Borras I, Umetsu DT. Rapid oral desensitization in combination with omalizumab therapy in patients with cow's milk allergy. J Allergy Clin Immunol. 2011; 127(6):1622-4.

45. Schneider LC, Rachid R, LeBovidge J, Blood E, Mittal M, Umetsu DT. A pilot study of omalizumab to facilitate rapid oral desensitization in high-risk peanut-allergic patients. J Allergy Clin Immunol. 2013;132(6):1368-74.

46. Foster B, Foroughi S, Yin Y, Prussin C. Effect of anti-IgE therapy on food allergen specific $\mathrm{T}$ cell responses in eosinophil associated gastrointestinal disorders. Clin Mol Allergy. 2011. doi:10.1186/ 1476-7961-9-7.

47. Kopp MV, Hamelmann E, Bendiks M, et al. Transient impact of omalizumab in pollen allergic patients undergoing specific immunotherapy. Pediatr Allergy Immunol. 2013;24(5):427-33.

48. Lemon-Mule H, Sampson HA, Sicherer SH, Shreffler WG, Noone $\mathrm{S}$, Nowak-Wegrzyn A. Immunologic changes in children with egg allergy ingesting extensively heated egg. J Allergy Clin Immunol. 2008;122(5):977-83, e1.
49. Nowak-Wegrzyn A, Bloom KA, Sicherer SH, et al. Tolerance to extensively heated milk in children with cow's milk allergy. J Allergy Clin Immunol. 2008;122(2):342-7, e1-2.

50. Kim JS, Nowak-Wegrzyn A, Sicherer SH, Noone S, Moshier EL, Sampson HA. Dietary baked milk accelerates the resolution of cow's milk allergy in children. J Allergy Clin Immunol. 2011; 128(1):125-31, e2.

51. Leonard SA, Sampson HA, Sicherer SH, et al. Dietary baked egg accelerates resolution of egg allergy in children. J Allergy Clin Immunol. 2012;130(2):473-80, e1.

52. Leonard SA, Martos G, Wang W, Nowak-Wegrzyn A, Berin MC. Oral immunotherapy induces local protective mechanisms in the gastrointestinal mucosa. J Allergy Clin Immunol. 2012;129(6): 1579-87, e1.

53. Kulis M, Macqueen I, Li Y, Guo R, Zhong XP, Burks AW. Pepsinized cashew proteins are hypoallergenic and immunogenic and provide effective immunotherapy in mice with cashew allergy. J Allergy Clin Immunol. 2012;130(3):716-23.

54. Shi X, Guo R, White BL, et al. Allergenic properties of enzymatically hydrolyzed peanut flour extracts. Int Arch Allergy Immunol. 2013;162(2):123-30.

55. Prickett SR, Voskamp AL, Phan T, et al. Ara h $1 \mathrm{CD}^{+} \mathrm{T}$ cell epitope-based peptides: candidates for a peanut allergy therapeutic. Clin Exp Allergy. 2013;43(6):684-97.

56. Pascal M, Konstantinou GN, Masilamani M, Lieberman J, Sampson HA. In silico prediction of Ara h $2 \mathrm{~T}$ cell epitopes in peanut-allergic children. Clin Exp Allergy. 2013;43(1):116-27.

57. Worm M, Lee HH, Kleine-Tebbe J, et al. Development and preliminary clinical evaluation of a peptide immunotherapy vaccine for cat allergy. J Allergy Clin Immunol. 2011;127(1): 89-97, e1-14.

58. Apostolovic D, Luykx D, Warmenhoven H, et al. Reduction and alkylation of peanut allergen isoforms Ara h 2 and Ara h 6; characterization of intermediate- and end products. Biochim Biophys Acta. 2013;1834(12):2832-42.

59. Starkl P, Felix F, Krishnamurthy D, et al. An unfolded variant of the major peanut allergen Ara h 2 with decreased anaphylactic potential. Clin Exp Allergy. 2012;42(12):1801-12.

60. Kulis $M$, Chen X, Lew J, et al. The $2 \mathrm{~S}$ albumin allergens of Arachis hypogaea, Ara h 2 and Ara h 6, are the major elicitors of anaphylaxis and can effectively desensitize peanut-allergic mice. Clin Exp Allergy. 2012;42(2):326-36.

61. Hilmenyuk T, Bellinghausen I, Heydenreich B, et al. Effects of glycation of the model food allergen ovalbumin on antigen uptake and presentation by human dendritic cells. Immunology. 2010;129(3):437-45.

62. Ilchmann A, Burgdorf S, Scheurer S, et al. Glycation of a food allergen by the Maillard reaction enhances its T-cell immunogenicity: role of macrophage scavenger receptor class A type I and II. J Allergy Clin Immunol. 2010;125(1):175-83, e1-11.

63. Shreffler WG, Castro RR, Kucuk ZY, et al. The major glycoprotein allergen from Arachis hypogaea, Ara h 1, is a ligand of dendritic cell-specific ICAM-grabbing nonintegrin and acts as a Th2 adjuvant in vitro. J Immunol. 2006;177(6):3677-85.

64. Zhou Y, Kawasaki H, Hsu SC, et al. Oral tolerance to foodinduced systemic anaphylaxis mediated by the C-type lectin SIGNR1. Nat Med. 2010;16(10):1128-33.

65. Rupa P, Nakamura S, Katayama S, Mine Y. Effects of ovalbumin glycoconjugates on alleviation of orally induced egg allergy in mice via dendritic-cell maturation and T-cell activation. Mol Nutr Food Res. 2014;58(2):405-17.

66. - Shan M, Gentile M, Yeiser JR, et al. Mucus enhances gut homeostasis and oral tolerance by delivering immunoregulatory signals. Science. 2013;342(6157):447-53. Identifies a novel mechanism of tolerance induction in the gastrointestinal tract that has translational potential for food allergy immunotherapy. 
67. Li XM, Srivastava K, Huleatt JW, Bottomly K, Burks AW, Sampson HA. Engineered recombinant peanut protein and heatkilled Listeria monocytogenes coadministration protects against peanut-induced anaphylaxis in a murine model. J Immunol. 2003;170(6):3289-95.

68. Frick OL, Teuber SS, Buchanan BB, Morigasaki S, Umetsu DT. Allergen immunotherapy with heat-killed Listeria monocytogenes alleviates peanut and food-induced anaphylaxis in dogs. Allergy. 2005;60(2):243-50.

69. - Li XM, Srivastava K, Grishin A, et al. Persistent protective effect of heat-killed Escherichia coli producing "engineered," recombinant peanut proteins in a murine model of peanut allergy. J Allergy Clin Immunol. 2003;112(1):159-67. Describes a novel therapeutic incorporating bacterial components and modified peanut allergens for immunotherapy delivered by the rectal route.

70. - Wood RA, Sicherer SH, Burks AW, et al. A phase 1 study of heat/phenol-killed, E. coli-encapsulated, recombinant modified peanut proteins Ara h 1, Ara h 2, and Ara h 3 (EMP-123) for the treatment of peanut allergy. Allergy. 2013;68(6):803-8. Describes the phase 1 study of the therapeutic developed in Reference 69. A unique example of pre-clinical study to human trial in food allergy research.

71. Kulis M, Gorentla B, Burks AW, Zhong XP. Type B CpG oligodeoxynucleotides induce Th1 responses to peanut antigens: modulation of sensitization and utility in a truncated immunotherapy regimen in mice. Mol Nutr Food Res. 2013;57(5): 906-15.

72. Creticos PS, Schroeder JT, Hamilton RG, et al. Immunotherapy with a ragweed-toll-like receptor 9 agonist vaccine for allergic rhinitis. N Engl J Med. 2006;355(14):1445-55.

73. Beeh KM, Kanniess F, Wagner F, et al. The novel TLR-9 agonist QbG10 shows clinical efficacy in persistent allergic asthma. J Allergy Clin Immunol. 2013;131(3):866-74.

74. Schmitz N, Dietmeier K, Bauer M, et al. Displaying Fel d1 on virus-like particles prevents reactogenicity despite greatly enhanced immunogenicity: a novel therapy for cat allergy. J Exp Med. 2009;206(9):1941-55.

75. Schulke S, Burggraf M, Waibler Z, et al. A fusion protein of flagellin and ovalbumin suppresses the $\mathrm{TH} 2$ response and prevents murine intestinal allergy. J Allergy Clin Immunol. 2011;128(6):1340-8, e12.

76. - Smarr CB, Hsu CL, Byrne AJ, Miller SD, Bryce PJ. Antigenfixed leukocytes tolerize Th2 responses in mouse models of allergy. J Immunol. 2011;187(10):5090-8. Describes the use of autologous cells as a "tolerogenic" adjuvant together with peanut antigen as immunotherapy.

77. Getts DR, Turley DM, Smith CE, et al. Tolerance induced by apoptotic antigen-coupled leukocytes is induced by PD-L1 ${ }^{+}$and
IL-10-producing splenic macrophages and maintained by $\mathrm{T}$ regulatory cells. J Immunol. 2011;187(5):2405-17.

78. Lutterotti A, Yousef S, Sputtek A, et al. Antigen-specific tolerance by autologous myelin peptide-coupled cells: a phase 1 trial in multiple sclerosis. Sci Transl Med. 2013;5(188):188ra175. doi:10.1126/scitranslmed.3006168.

79. Liu Y, Sun Y, Chang LJ, et al. Blockade of peanut allergy with a novel Ara $\mathrm{h}$ 2-Fcgamma fusion protein in mice. J Allergy Clin Immunol. 2013;131(1):213-21, e1-5.

80. Kulis M, Li Y, Lane H, Pons L, Burks W. Single-tree nut immunotherapy attenuates allergic reactions in mice with hypersensitivity to multiple tree nuts. J Allergy Clin Immunol. 2011;127(1):81-8.

81. Thyagarajan A, Jones SM, Calatroni A, et al. Evidence of pathway-specific basophil anergy induced by peanut oral immunotherapy in peanut-allergic children. Clin Exp Allergy. 2012;42(8): 1197-205.

82. Song Y, Qu C, Srivastava K, et al. Food allergy herbal formula 2 protection against peanut anaphylactic reaction is via inhibition of mast cells and basophils. J Allergy Clin Immunol. 2010; 126(6): 1208-17, e3.

83. Srivastava KD, Kattan JD, Zou ZM, et al. The Chinese herbal medicine formula FAHF-2 completely blocks anaphylactic reactions in a murine model of peanut allergy. J Allergy Clin Immunol. 2005;115(1):171-8.

84. Masilamani M, Wei J, Bhatt S, Paul M, Yakir S, Sampson HA. Soybean isoflavones regulate dendritic cell function and suppress allergic sensitization to peanut. J Allergy Clin Immunol. 2011; 128:1242-50.

85. Yamaki K, Yoshino S. Remission of food allergy by the Janus kinase inhibitor ruxolitinib in mice. Int Immunopharmacol. 2013;18(2):217-24.

86. Yamaki K, Yoshino S. Preventive and therapeutic effects of rapamycin, a mammalian target of rapamycin inhibitor, on food allergy in mice. Allergy. 2012;67(10):1259-70.

87. Sampson HA, Leung DY, Burks AW, et al. A phase II, randomized, double blind, parallel group, placebo controlled oral food challenge trial of Xolair (omalizumab) in peanut allergy. J Allergy Clin Immunol. 2011;127(5):1309-10, e1.

88. Elazab N, Mendy A, Gasana J, Vieira ER, Quizon A, Forno E. Probiotic administration in early life, atopy, and asthma: a metaanalysis of clinical trials. Pediatrics. 2013;132(3):e666-76.

89. Atarashi K, Tanoue T, Shima T, et al. Induction of colonic regulatory $\mathrm{T}$ cells by indigenous Clostridium species. Science. 2011;331(6015):337-41.

90. - Atarashi K, Tanoue T, Oshima K, et al. Treg induction by a rationally selected mixture of Clostridia strains from the human microbiota. Nature. 2013;500(7461):232-6. Describes the therapeutic potential of human commensal bacterial strains. 